\title{
Utilização de Tecnologias de Informação como Ferramenta Didática em Escolas Públicas no Estado de Pernambuco
}

\author{
Wagner Henrique Matias de Carvalho, Wágner Bruno Silva Coelho
}

\begin{abstract}
Resumo: Este trabalho tem o objetivo de comentar a utilização de tecnologias de informação como ferramenta didática em escolas públicas de Pernambuco. Consiste em uma revisão integrativa, de caráter exploratório. Com o expressivo progresso do conhecimento de forma global, o emprego de tecnologias de informação e comunicação passaram a ser ferramentas fundamentais em nossas vidas. Essas tecnologias de informação e comunicação ainda não estão disponíveis para todos, mas revolucionaram distintos campos da sociedade e originaram grandes mudanças na educação. Este estudo teve importância imperiosa para a ponderação e discussão das TIC, pois demonstrou que a utilização das TIC, auxiliam de forma bastante positiva a didática dos professores e insere a escola em um plano de desenvolvimento mais alinhado com a modernidade. No estado de Pernambuco, alguns projetos foram agregados, mas, necessita-se de maior alcance, para que toda a rede educacional presencie e desenvolva tecnologias de informações em seu dia-a-dia, para que possa ser aprimorada ainda mais a didática, implicando em melhoria da aprendizagem.
\end{abstract}

Palavras-chaves: Educação. Didática. Tecnologia.

\section{The use of Information Technologies as a Teaching Tool in the Public Schools of the State of Pernambuco}

\begin{abstract}
This work aims to comment on the use of information technology as a teaching tool in public schools in Pernambuco. It consists of an integrative, exploratory review. With the expressive progress of the knowledge in a global way, the use of information and communication trough technologies have become a fundamental tools in our lives. These information and communication technologies are not yet available to everyone, but have revolutionized different fields of society and brought about major changes in education. This study had an imperative importance for the weighting and discussion of ICTs, since it demonstrated that the use of ICT helps in a very positive way the didactics of teachers and inserts the school into a development plan more aligned with modernity. In the state of Pernambuco, some projects have been added up but more scope is needed for the whole educational network to witness and develop information technologies in their daily lives, so that the didactic can be further development, implying in improving learning.
\end{abstract}

Keywords: Education. Didactics. Technology.

\footnotetext{
${ }^{1}$ Universidade Federal do Vale do São Francisco - UNIVASF. Curso de Gestão Pública. Contato: wagner_whmc50@hotmail.com;

${ }^{2}$ Graduação em Fisioterapia pela Faculdade Leão Sampaio. Especialista em saúde pública pela FAK e em Gestão em Saúde pela Universidade Federal do Vale do São Francisco - UNIVASF. Contato: drbrunocoelho@ hotmail.com.
} 


\section{Introdução}

O ensino no meio escolar consiste em perseguir objetivos, ao mesmo tempo, de socialização e de instrução, num contexto de interação com os alunos, servindo-se de alguns "instrumentos" de trabalho: tecnologia de informações, diretrizes do Ministério da Educação, programas, orientações pedagógicas, manuais para atingi-los (DOWBOR, 2001).

A finalidade essencial das escolas é a socialização técnica e moral dos alunos. Elas objetivam aparelhar os jovens para vida adulta, formando-os para os saberes e as habilidades necessárias à vida básicas (LUCKESI, 2015).

A maioria dos países verificaram que as finalidades escolares ampliaram-se desde os anos de 1960, procurando agregar os saberes contemporâneos, como as ciências sociais e humanas, tecnologias e ciências naturais e por outro lado harmonizar a escola com as frequentes inquietações da economia, o que se traduziu pela introdução de novas matérias como a informática, estatística e de novas técnicas de aprendizagem: ensino a distância, ensino programado entre outros (LUCKESI, 2015).

$\mathrm{Na}$ realidade, a educação continua o trabalho da vida, instalando-se no domínio eminentemente humano de trocas: símbolos, intenções, padrões de cultura e relações de poder, devendo assumir, sempre, a perspectiva de continuidade ao desenvolvimento de homens e mulheres, fazendo-os evoluir, tornando-os mais humanos (GOLDENSTEIN, 2009).

Dado o reconhecimento de que o ensino constitui uma ação social fundamental, o que em outros termos, é a construção da personalidade humana e de saberes, destaca-se a importância de buscar novas ferramentas tecnológicas de gestão pedagógica para intervenções educacionais no cotidiano da sala de aula.

Tal situação requer, conforme nos incita Paulo Freire (2000), que lancemos mão da ousadia para permanecermos na educação. Essa solicitação, que expressa o surgimento de tecnologias de informação.

As inovações tecnológicas, que surgem no mundo globalizado da mídia eletrônica, estão implicando em configurações distintas da vida social contemporânea e levando a ressignificações de conceitos, tais como o de infância, juventude, velhice, família, inclusão ou exclusão social e muitos outros, pois remodelam sociedades e identidades em todo o mundo (ZUIN, 2010). 
A tecnologia é um dos elementos constituintes fundamentais da modernidade. Ela transformou a forma de viver e de se relacionar do indivíduo, além de provocar desenvolvimento científico e tecnológico. Com o transcorrer do tempo, o modo como nos relacionamos com as grandezas tecnológicas também se decompõe e traz novas mudanças sobre as formas de ensinar, aprender e se comunicar (BIANCHI; PIRES; VANZIN, 2009).

A história das tecnologias na educação, nos EUA, se inicia na década de 70, com o desenvolvimento e uso de programas tipo CAI (Computer Aided Instruction), fundamentado em teorias comportamentalistas que direcionam a utilização do computador como máquina de instruir a educação, através de um software de instrução planejada, os quais foram transformados em produtos industriais por grandes empresas do setor, tais como IBM, RCA etc (ALMEIDA, 2008).

Os anos 80 são caracterizados pelo construcionismo, além da desvalorização dos media literacy. Na década de 90, existiu um retorno, dessa vez com uma maior excitação a essas práticas nas escolas e um desenvolvimento no âmbito educativo que atribui maior autonomia e flexibilidade ao professor. Nos anos 2000, as políticas públicas estimulam a integração das tecnologias de informações ao currículo (ALMEIDA, 2008).

Atualmente, um dos maiores desfiados ainda é tornar o acesso às tecnologias de informação de forma universal, para assim, abranger todo o contingente de alunos brasileiros, docentes e estabelecimentos escolares, e desta forma, expandir a compreensão de que o embasamento conceitual para o uso de tecnologias na educação é a integração das tecnologias de informação ao currículo, ao ensino e à aprendizagem ativa, numa ótica de mutação da escola e da sala de aula em um espaço de conhecimento, de desenvolvimento de cidadãos e de vivência democrática, desenvolvido pela presença dessas tecnologias.

Diante do que foi exposto, surge uma indagação, a qual, se faz como a problemática deste estudo: Como as tecnologias de informação estão sendo utilizadas para melhorar a didática no ensino das escolas públicas no estado de Pernambuco?

Este trabalho tem o intuito de adquirir conhecimentos, coletar informações importantes sobre o uso de tecnologias de informação no ensino para melhora da didática das escolas públicas no estado de Pernambuco, para transformar os resultados em informações para acadêmicos, profissionais e toda a classe científica, e dessa forma denotar a fundamentação de sua importância no processo de desenvolvimento educacional. 
Este trabalho tem o objetivo geral de verificar a utilização de tecnologias de informação para melhora da didática das escolas públicas no estado de Pernambuco.

\section{Metodologia}

O estudo realizado consiste em uma revisão bibliográfica integrativa, de caráter exploratório.

A pesquisa bibliográfica é distinguida pelo desenvolvimento do estudo a partir de materiais já finalizados, sendo constituído de livros, monografias, dissertações e artigos científicos (MARQUES; PECCIN, 2005). Trata-se de uma pesquisa com coleta de dados concretizada por meio do levantamento de literaturas (DE SOUZA; DA SILVA; DE CARVALHO, 2010).

Tem caráter exploratório, pois proporciona mais estudos sobre o determinado problema, tornando-o explícitos e construindo hipóteses. Institui uma finalidade de desenvolver investigações ou definir problemas, tendo em vista de estabelecer proposições, acrescentando uma maior intimidade do pesquisador com o objeto de estudo, acontecimento ou por algum feito, converter ideias e explanar dúvidas (MARCONI; LAKATOS, 2010).

Foram utilizados três artigos para esta discussão, conforme a tabela 1, a seguir.

Tabela 1: Estudos pesquisados.

\begin{tabular}{l|c|c}
\hline Título & Autor & Ano de publicação \\
\hline $\begin{array}{l}\text { Plano de Intervenção para } \\
\begin{array}{l}\text { Expansão de Pontos de } \\
\text { Telessaúde no Município do } \\
\text { Cabo de Santo Agostinho - PE }\end{array}\end{array}$ & 2012 \\
\hline $\begin{array}{l}\text { Análise do Programa } \\
\begin{array}{l}\text { Telessaúde Brasil Redes no } \\
\text { estado de Pernambuco no } \\
\text { período de 2007 a 2011 }\end{array}\end{array}$ & Silva, Pietro Reis Lopes da \\
\hline $\begin{array}{l}\text { Tele-educação para educação } \\
\text { continuada das equipes de saúde } \\
\text { da família em saúde mental: a } \\
\begin{array}{l}\text { experiência de Pernambuco, } \\
\text { Brasil }\end{array}\end{array}$ & $\begin{array}{c}\text { Novaes, Magdala de Araújo; Machiavelli, } \\
\text { Josiane Lemos; Verde, Filipe Cesário Villa; } \\
\text { Campos Filho, Amadeu Sá de; Rodrigues, } \\
\text { Tereza Roberta Castro. }\end{array}$ & 2013 \\
\hline
\end{tabular}

Fonte: dados da pesquisa, 2018. 
Para busca dos artigos, utilizou-se os seguintes descritores na língua portuguesa: “Tecnologia", "Ensino", e "Pernambuco". O banco de dados utilizado foi o LILACS, por ter seu acesso de forma gratuita.

Realizou-se uma leitura primária, onde foram utilizados somente os resumos dos trabalhos, a partir dessa leitura, foram selecionados os estudos. Estes passaram por a uma leitura secundária, em sua íntegra, para realização dos resultados do trabalho.

Dentre os critérios de inclusão, foram empregados artigos científicos, de circulação nacional, com período de publicação de 2012 a 2017. Como critério de exclusão, foram excluídos do estudo artigos não científicos, bem como artigos que não fizessem parte da base de dados acima descrita e artigos fora do período especificado.

Após a busca na base de dados descrita, foram expostas todas as informações colhidas sobre a temática apresentada. Os estudos foram analisados de forma completa, sendo extraídos fragmentos importantes para o trabalho, estes em forma de citação direta ou indireta. Os resultados foram discutidos com estudos de outros autores para assim dar maior fidedignidade aos resultados obtidos.

\section{Resultados}

Foram encontrados 09 estudos, utilizando a combinação dos descritores: "Tecnologia", "Ensino" e, "Pernambuco". Foram excluídos 2 estudos por apresentarem data inferior a 2007, 1 por não ser na língua nacional, 3 por não contextualizar com o objetivo desse trabalho. Desta forma verifica-se uma escassez desse tema no município, totalizando a amostra em 3 estudos, sendo estes, expressos na tabela a seguir:

No estudo de Silva (2012), relata que uma das formas de tecnologias de informações que foram aplicadas em Pernambuco foi uma Telessaúde Aplicada à Atenção Primária, denominada Rede NUTES, que são pontos de telessaúde implantados em unidades da rede pública de saúde, prioritariamente em Unidades de Saúde da Família (USFs), dos municípios das 11 (onze) Gerências Regionais de Saúde (GERES). Cada ponto desse, apresenta um kit multimídia e mobiliário conectado à Internet com banda larga com conexão satisfatória para o 
emprego dos serviços de tele-educação ou teleassistência. Observou-se nesse, resultados positivos no que se refere seu grau de implantação em Pernambuco.

Silva (2013) em seus estudos relata que o uso de tecnologias de informações, por meio da telessaúde, promoveu retaguarda a serviços de saúde, contribuindo numa maior resolutividade da rede de saúde. Relata também que a tecnologia de informação e telecomunicações deve ser aproveitada para corroborar a prática profissional, constando ensino a distância, acesso eletrônico à literatura e sistemas de apoio à decisão, propendendo a suprir necessidades de usuários, profissionais, gestores, instituições de ensino, pesquisa e controle social, estabelecendo convênios específicos com os municípios para aquisição dos equipamentos.

Novaes et al. (2011) afirma que as tecnologias da informação, especialmente a internet, por meio das suas redes e comunidades sociais virtuais, são poderosos instrumentos para a comunicação e o acesso às informações, e a Telessaúde assume um papel importante, pois favorece a criação de serviços colaborativos entre profissionais e especialistas trabalhando remotamente. $\mathrm{O}$ autor afirma que a implementação da tele-educação ainda enfrenta obstáculos em Pernambuco, sendo um deles, a conectividade.

\section{Tecnologias de Informação}

As tecnologias de informação podem ser definidas como recursos não humanos (Softwares ou hardwares), destinadas ao armazenamento, processamento e a transmissão da informação (NÓBREGA; GARCIA, 2009).

As tecnologias de informação constituem um sistema de Informação que tem como propósito coligar elementos inter-relacionados que recolhem (ou restauram), processam, armazenam e disseminam informações dedicadas a condicionar a informação e dar assistência ao apoio às decisões aos usuários de uma determinada organização. Os sistemas de informação também trabalham com informações sobre pessoas, locais, itens significativos para qualquer tipo de organização ou para o ambiente em que os sistemas de informações esteja plantado (MAIA, 2011). 
Estes serviços podem ser desde desenvolvimento de aplicativos, como desenvolvimento de sites, instalações de software, manutenção de hardware e práticas implementarias de soluções tecnológicas que colaborem para o funcionamento de um sistema de informação (MAIA, 2011).

Essas tecnologias de informação são instrumentos que melhoram o subsídio de gestão a informação, agilizando o fluxo das informações e fazendo com que sua transmissão se torne mais eficiente tornando mais ágil e eficiente e, facilitando, as tomadas de decisões (FERNANDES, 2008).

As tecnologias de informação acontecem em consequência de três grandes vertentes técnicas: a informática, as telecomunicações e as mídias eletrônicas. As expectativas de uso são infinitas e inexploradas e vão desde casas ou automóveis inteligentes até os androides reais e virtuais para propósitos distintos, incluindo toda a diversidade dos jogos on line (BIANCHI; PIRES; VANZIN, 2009).

\section{Uso de Tecnologias de Informação no Ensino}

Ao refletir sobre o uso da tecnologia na educação, almeja-se que esta seja útil para educar, ou seja, um conhecimento que possibilite a organização de ambientes de aprendizagem que consintam aos professores e alunos qualidades adequadas para alcançar seus propósitos educativos (BIANCHI; PIRES; VANZIN, 2009).

A maior inserção dessas tecnologias de informações no campo educacional, cumprem importante desempenho na universalização e qualidade do ensino, provoca uma formação apropriada e mudança de perfil do profissional da educação para enfrentar esses novos desafios (MARQUES, 2006).

Dessa forma, a utilização das tecnologias de informações no campo educacional apresenta grandes benefícios no processo de ensino-aprendizagem, pois acomete a linguagem virtualizada tão presente na cultura dos alunos, misturando som, imagens e palavras.

Mas, sua inserção mesmo estando presente, apresenta alguns problemas, como pode ser visto na argumentação a seguir.

De acordo com Bianchi, Pires e Vanzin, (2009, p. 57): 
Por mais potentes que sejam os computadores ou por mais velozes que sejam as redes de transmissão, não irão acabar com todos os problemas que envolvem a questão da inserção de tecnologias na educação, pois as tecnologias têm implicações políticas, econômicas, sociais e culturais que precisam ser observadas com a maior atenção quando introduzidas em espaços educativos (BIANCHI, PIRES E VANZIN, 2009, p. 57)

Assim, as tecnologias de informações se tornam redes colaborativas, permitindo a interação entre duas ou mais pessoas, a troca de informações, a realização de pesquisas coletivas entre grupos distanciados geograficamente e, principalmente, possibilitam a produção de novos conhecimentos, através da mediação do professor (KENSKI, 2007).

\section{Transformação Social através da Educação}

A transformação do contexto social só é possível realizar através da reflexão em relação à educação, pensada no ser humano. Pensemos antes sobre nós mesmos e tratemos de nos encontrar como seres atuantes na natureza, que possam constituir a base fundamental que se sustenta o processo de educação (FREIRE, 2014).

A educação não existiria se o homem fosse um ser acabado. O indivíduo reflete sobre essas possíveis suposições na sua realidade de acordo com um determinado momento. Com isso, ele busca constantemente descobrir como ser inacabado resultando na busca pela educação (ENGUITA, 2007).

A educação é a busca da finitude para este homem, sujeito de sua própria educação, por isso, ninguém educa ninguém. A Educação tem caráter permanente, não existem seres educados e não educados, estamos todos num processo de educação e existem graus de educação. Não podemos nos colocar na posição do ser superior que ensina um grupo de ignorantes, mas sim na posição humilde daquele que comunica um saber relativo a outros que possuem um saber relativo (TRIVIÑOS, 2015).

No contexto social existe uma necessidade de imposição aos demais numa espécie da chantagem de amor. Ama-se na medida em que busca comunicação, integração e relação com os demais. Não existe educação sem amor, quem não é capaz de amar os seres inacabados não 
podem educar. Não há educação imposta como não há amor imposto. Não há educação do medo (SOBRINHO, 2010).

Uma educação sem esperança não é educação. Quem não tem esperança na educação deve trabalhar com outro ofício. As características desta relação é a de refletir sobre o mesmo ato, exige uma reflexão do homem frente à realidade. Se a educação pretende adaptar o homem ao contexto social, a mesma precisa ajuda-lo as adaptações necessárias para convivência e sobrevivência no contexto social, caso contrário estará matando as possibilidades de ação do mesmo a sua sobrevivência e superação (BRANDÃO, 2017).

A educação está para estimular o homem e integrá-lo e não o acomodar. O professor ainda se apresenta como um ser superior que ensina ignorante e acaba gerando seres com consciência bancaria, onde o aluno recebe passivamente os conhecimentos tornando-se um deposito. Porém o destino deve criar para transformar o mundo e se tornar sujeito da sua própria criação (MANFREDI, 2017).

A prática docente de educadores críticos exige a presença de educandos criativos, instigador, curioso e persistente, faz parte do aprendizado crítico, com produção de saberes transformando sujeitos da construção e reconstrução do saber ensinado (BECKER, 2016).

\section{Didática e o uso de Tecnologia no Ensino}

O desígnio do termo "didática”, “didático”, é apreciado desde a Grécia, que quer referir a o ato de ensinar, contemporâneo entre os mais experientes e os mais imaturos, de pequeno até o desenvolvimento, na família e nos demais espaços sociais e públicos (LIBANEO, 2017).

Essa didática - ação de ensinar de um Sócrates começa a ganhar contornos de campo específico e autônomo a partir do século XVII, com o monge luterano João Amós Comênio (1592-1670), que escreve, entre 1627 e 1657, a obra Didática Magna - Tratado da arte universal de ensinar tudo a todos, foram definidas como pilares da instrução pública, necessária, à época, para a vitória da Reforma Protestante (FAZENDA, 2015).

Sem sombra de dúvida, encontramos em Comênio as bases para generalização da escola a toda a população, requisito e demanda do desenvolvimento comercial, da constituição das cidades, bem mais adiante, do capitalismo industrial final do século XIX (DOURADO, 2015). 
A didática comeniana tem seu embasamento na própria natureza, fornece em seu processo evolutivo as bases para o ensino: do simples para o complexo. Cada etapa em seu tempo, ou seja, todo fruto amadurece, mais precisa de condições adequadas, ou seja, o curso dos estudos é distribuído por anos, meses, dias e horas; e enfim, é indicado um caminho fácil e seguro para pôr essas coisas em prática com bom resultado (LIBANEO, 2017).

No Brasil, quando a Didática foi estabelecida como curso de licenciatura (1939) e, mais tarde, decomposta em uma disciplina dos cursos de formação de professores (1946), dominouse o enfoque prescritivo, normativo e instrumental. Suas apreensões foram diminuídas ao “como ensinar"; ficou situada na expedição de normas e regras do "bem fazer", uniformizando não só as ações didáticas a serem concretizadas pelos professores, como vinculando nestes uma só lógica de ver e estar no mundo, ou seja, o pensamento liberal sobre a sociedade, a educação e a escola, a aprendizagem e o aluno (LIBANEO, 2017).

A didática teve uma configuração de disciplina prescritiva, pois predominava uma prática pedagógica tradicional, cuja tônica foi à transmissão das verdades incontestáveis da Igreja Católica e da Ciência positivista, bem como da assimilação acrítica e passiva da cultura do dominador pelos dominados através dos exercícios de repetição (DOURADO, 2015).

No ano de 1970 no Brasil os educadores brasileiros entram em contato com as teorias crítico-reprodutivista, rebelando-se contra a institucionalização da Pedagogia Tecnicista. Neste momento, reina a "antididática" Candau (1983, p.15), ou seja, a Didática da afirmação do político e da negação do técnico; da denúncia do caráter alienado e alienador dos processos de formação e do seu atrelamento aos mecanismos de reprodução do sistema social capitalista; a Didática contra tudo que não promovesse a consciência e a militância política dos professores, em defesa de outro modelo social, atuando em frente muito além dos muros da escola; um movimento de rompimento das fronteiras disciplinares e, consequentemente, de grande aproximação da didática com a Sociologia e a Filosofia da educação; fato considerado, por uns como tempo de uma identidade perdida e, por outros, como ritual de passagem necessário à terceira possibilidade teórica da Didática: a Didática crítica, ”o movimento da síntese ou da negação da negação" (CANDAU, 1983,p.16).

Surge a Didática crítica como o terceiro elo da tríade do pensamento dialético: tese, antítese e síntese, ficaram instituídas como momento da superação de duas posições anteriores 
e opostas (a didática instrumental e a antididática), ilustrado pela Teoria da Curvatura da Vara, enunciada por Lênin (FAZENDA, 2015).

Uma didática que articula teoria e prática, escola e sociedade, conteúdo e forma, técnica e política, ensino e pesquisa; uma didática que concebe os professores como sujeitos que aprendem uma profissão e se fazem profissionais na medida em que aprendem ensinando (NICOLETE et al., 2016).

Um novo momento é o impacto das tecnologias de informação e comunicação sobre a produção e socialização do conhecimento sobre a formação de profissionais com o surgimento da sociedade do conhecimento ou da aprendizagem (DOURADO, 2015).

Com o desenvolvimento do conhecimento e sua produção, as áreas da ciência se aproximaram: os fenômenos a serem explicitados e compreendidos exigem mais do que apenas uma abordagem, um especialista, uma explicação. A multidisciplinaridade e a interdisciplinaridade são chamadas para trazer sua contribuição ao desenvolvimento da ciência. A interação entre as ciências exatas e humanas torna-se uma exigência para o desenvolvimento do mundo e da comunidade humana (FAZENDA, 2015).

As diferentes técnicas permitem e exploram o uso de recursos das tecnologias de informação e comunicação que pertencem ao mundo e a vida dos alunos: internet, games que representam as mais variadas ocasiões profissionais, hipermídia, visitas técnicas profissionais em situações de alto risco ou de difícil acesso.

As técnicas que se dispõem para incentivar o aluno a aprender e ajudá-lo a alcançar sua formação profissional só poderão fazê-lo se usadas como instrumentos para alcançar objetivos de aprendizagem e se elas forem eficientes para isso. Essas técnicas existem para ajudar os alunos a desenvolver seu processo de aprendizagem em todas as áreas (NICOLETE et al., 2016).

As tecnologias de informação e comunicação (TICs) constituem um novo caminho nas estratégias de aprendizagem o advento da informática e da telemática, o processo educacional adquiriu novas possibilidades tanto na dimensão de educação à distância como em seu aspecto de apoio à aprendizagem presencial nas aulas da universidade (DOURADO, 2015).

Ocasionou também a conveniência de expandir a autoaprendizagem e a Inter aprendizagem a distância, por meio dos computadores que se encontram mais distintos locais. 
O professor necessita ter uma postura respeitável na aplicação da técnica, deve se convencer de que a participação do aluno durante a aula e fora dela é vital para sua aprendizagem, o professor precisa adquirir o papel de mediador no processo de aprendizagem, com atitudes de parceria e trabalho, constituir objetivos muitos claros de aprendizagem e organizar um programa construído coletivamente para sua consecução em um ambiente que inspire confiança entre professor e alunos (RODRIGUES, 2007).

O professor como planejador de situações de aprendizagem, envolvido e comprometido com o processo de desenvolvimento de seus alunos e disposto a encontrar as melhores condições, não para fazer suas preleções, mas para que o aluno se interesse pela própria formação e trabalhe por ela com eficiência e eficácia (DOURADO, 2015).

\section{Tecnologias de Informação nas Escolas Públicas do Estado de Pernambuco}

No estado de Pernambuco, através do governo do estado, vários projetos foram alcançando destaque, no que diz respeito a inserção de tecnologias de informação no ensino público. Como exemplo de avanço no serviço de tecnologias de informação, foi a publicação da Lei Estadual $n^{\circ}$ 14.546, de 21 de dezembro de 2011, que designou o Programa Aluno Conectado - PAC no âmbito das unidades públicas de ensino do Estado (MONTE, 2016).

Dentre os programas de informatização no ensino, os projetos que ganharam destaque foram: a doação de notebooks para os docentes, a doação de "tablets" a alunos da rede estadual de ensino, através do programa Aluno Conectado, o projeto ProInfo - Programa Nacional de Tecnologia Educacional, com a criação e doação de aparelhos retroprojetores com sistema wireless, ele permite o acesso à internet, entre outros (PERNAMBUCO, 2012).

A secretaria do estado de Pernambuco também está contribuindo com envio de novos computadores para os laboratórios das escolas e também com a substituição de computadores mais antigos (PERNAMBUCO, 2012).

Uma das formas de integração entre educadores, alunos, pais e responsáveis mo ensino público, foi a criação do projeto gestor móvel, que funciona por meio do serviço de rede sem fio que fora implantado nas escolas, permitindo a melhoria na qualidade do ensino através da troca de informações em tempo real (MONTE, 2016). 
Todos esses programas levam ao processo de melhoria do acesso a informação por meio tecnológico, melhorando a didática nas redes de ensino público do município de Pernambuco (MONTE, 2016).

\section{Conclusões}

Com o expressivo progresso do conhecimento de forma global, o emprego de tecnologias de informação e comunicação, passaram a ser ferramentas fundamentais em nossas vidas.

Essas tecnologias de informação e comunicação ainda não estão presentes para todos, mas revolucionaram distintos campos da sociedade e originaram grandes mudanças na esfera da educação.

Este estudo teve importância imperiosa para a ponderação e discussão das TIC, porque demonstrou que a utilização das TIC, auxiliam de forma bastante positiva a didática dos professores e insere a escola em um plano de desenvolvimento em sintonia com a sociedade atual.

No estado de Pernambuco, alguns projetos foram agregados, mas, necessita-se de maior alcance, para que toda a rede educacional presencie e desenvolva tecnologias de informações em seu dia-a-dia. Urge aí um aprimoramento da didática, no sentido de agregar as novas modalidades de tecnologias disponíveis, de forma a facilitar a aprendizagem.

Na rede de saúde, o programa de telessaúde virou destaque no estado, desenvolvendo ferramentas para a disseminação de ensino em saúde, o que precisa também abranger as escolas públicas do Estado.

\section{Referências}

ALMEIDA, Maria Elizabeth Bianconcini. Tecnologias na Educação: dos caminhos trilhados aos atuais desafios. Boletim de Educação Matemática, v. 21, n. 29, 2008.

BECKER, Fernando. Educação e Construção do Conhecimento: Revista e Ampliada. Penso Editora, 2016. 
BIANCHI, Paula; PIRES, Giovani De Lorenzi; VANZIN, Tarcízio. As Tecnologias de Informação e Comunicação na Rede Municipal de Ensino de Florianópolis: possibilidades para a educação (física). Revista Linhas, v. 9, n. 2, 2009.

BRANDÃO, Carlos Rodrigues. O que é educação. Brasiliense, 2017.

CANDAU, V. M. (Org.). A Didática em questão. Rio de Janeiro: Vozes, 1983.

DOURADO, Irismar de França et al. Uso das TIC no Ensino de Ciências na Educação Básica: uma Experiência Didática. Revista de Ensino, Educação e Ciências Humanas, v. 15, 2015.

DOWBOR, Ladislau. Tecnologias do conhecimento: os desafios da educação. Petrópolis: Vozes, p. 30. São Paulo, 2001.

ENGUITA, Mariano Fernández et al. Educação e transformação social. 2007.

FAZENDA, Ivani Catarina Arantes. Interdisciplinaridade: didática e prática de ensino. Interdisciplinaridade. Revista do Grupo de Estudos e Pesquisa em Interdisciplinaridade. ISSN 2179-0094., n. 6, p. 9-17, 2015.

FERNANDES, Sérgio Alexandre Simões. Sistemas de informação geográfica na gestão de campos de golfe: enquadramento teórico e caso de estudo do campo do golfe da Quinta do Lago. Tese de Doutorado. 2008.

FREIRE, Paulo. Pedagogia da indignação cartas pedagógicas e outros escritos. 2000.

FREIRE, Paulo. Educação e mudança. Editora Paz e terra, 2014.

GOLDENSTEIN, Marlene Seica. Produção de conhecimento e atividade formativa: uma proposta para educadores autor. Tese de doutorado. Campinas, SP: [s.n.], 2009.

KENSKI, Vani Moreira. Educação e tecnologias: o novo ritmo da informação. Campinas: Papirus, 2007.

LIBÂNEO, José Carlos. didática. Cortez Editora, 2017.

LUCKESI, Cipriano Carlos. Tendências pedagógicas na prática escolar. Filosofia da Educação. São Paulo: Cortez, 2005.

MAIA, Ulisses Barros de Abreu. O uso das tecnologias de informação como instrumentos de poder no pentecostalismo brasileiro. Anais dos Simpósios da ABHR, v. 12, n. 1, 2011.

MANFREDI, Silvia Maria. Educação profissional no Brasil: atores e cenários ao longo da história. Paco Editorial, 2017. 
MARQUES, Mário Osório. A escola no computador: linguagens rearticuladas, educação outra. $2^{\text {a }}$ ed. Ijuí: UNIJUÍ, v. 2, 2006.

MONTE, Marciel José. Programa Aluno Conectado: analisando a utilização do computador para a Educação Estatística em escolas de Pernambuco. XX EBRAPEM. 2016.

NICOLETE, Priscila Cadorin et al. Integração de tecnologias no ensino da matemática na educação fundamental pública. Seminário de Pesquisa, Pós-Graduação e Inovação, 2016.

NÓBREGA, Maria Miriam Lima; GARCIA, Telma Ribeiro. Classificação Internacional para a Prática de Enfermagem: instrumental tecnológico para a prática profissional. Revista Brasileira de Enfermagem, v. 62, n. 5, 2009.

PERNAMBUCO, Secretaria de Educação. Tecnologias nas escolas: conectando ideias. 2012.

RODRIGUES, João. Formação inicial de professores no uso das TICS para o ensino de biologia da Universidade Federal do Amazonas. Revista Areté| Revista Amazônica de Ensino de Ciências, v. 9, n. 19, p. 176-187, 2017.

SILVA, Pietro Reis Lopes da. Plano de Intervenção para Expansão de Pontos de Telessaúde no Município do Cabo de Santo Agostinho - PE. Monografia apresentada ao Curso de Especialização em Gestão de Sistemas e Serviços de Saúde do Departamento de Saúde Coletiva, Centro de Pesquisas Aggeu Magalhães, Fundação Oswaldo Cruz. Recife-PE. 2012.

SOBRINHO, José Dias. Avaliação e transformações da educação superior brasileira (19952009): do provão ao SINAES. Avaliação: Revista da Avaliação da Educação Superior, v. 15, n. $1,2010$.

TRIVIÑOS, A. N. S. Introdução à pesquisa em ciências sociais: a pesquisa qualitativa em educação. $23^{\text {a }}$ reimpr. São Paulo: Atlas, 2015.

ZUIN, Antonio AS. O Plano Nacional de Educação e as tecnologias da informação e comunicação. Educação \& Sociedade, v. 31, n. 112, 2010.

Como citar este artigo (Formato ABNT):

CARVALHO, Wagner Henrique Matias de; COELHO, Wágner Bruno Silva. Utilização de Tecnologias de Informação como Ferramenta Didática no Estado de Pernambuco. Id on Line Rev.Mult. Psic., 2018, vol.12, n.42, p. 486-500. ISSN: 1981-1179.

Recebido: 12/09/2018;

Aceito: 29/09/2018 